\title{
The wider dental team
}

\author{
Stephen Hancocks OBE \\ Editor-in-Chief
}

September is out. The year and seasons march on and with the fading strains of The Last Night of The Proms ringing out the lyrics 'wider still and wider', we plunge past the equinox of equal light and dark into longer evenings and gloomier mornings.

The autumn however brings its own delights, the BDTA's Showcase event being a highlight in the dental world and reminding us, amongst other things, that we have partners in a wider dental team than the folk who familiarly populate our daily lives and share our practice spaces. We do well to remember such extended families from time to time since, bluntly, we could not manage to undertake the patient care that we do without the products and services of the dental trade. Similarly it has to be noted that they would not be able to survive without us but the symbiosis is essential, if not always consciously acknowledged.

Behind the booth-fronts, pull-up banners, give-away goodies and piles of literature there dwell yet another set of colleagues who beaver away researching better products, more efficient preventive agents and formulations, improved materials and effective equipment. Take toothpaste, for example, or dentifrice as the marketing parlance seems to rather haughtily prefer (do people really refer to it by this term I wonder? - 'darling it's time to pop up to bed now and do remember to brush with dentifrice first'). Smirking aside, what an amazing agent for good this has proved to be and will I have no doubt continue to prove to be in improving oral health. Fluoride alone has saved countless millions of teeth and billions of paroxysms of distress, yet this amongst other developments we take very much for granted.

\section{NOT NECESSARILY BENEFICIAL}

Other partnerships or alliances are also very apparent in our daily lives. Political and bureaucratic interfaces loom large not only within the NHS and its inherent need to prescribe, measure and assess but also increasingly throughout all forms of practice. The Care Quality Commission might be such an example but there are others.

However, not all partnerships are necessarily happy, positive, co-operative and beneficial; we do not have any illusions about this in life in general so we should not be surprised if this is reflected in life in dentistry too. Indeed, my concern is that we are in danger of over-egging the pudding, or more accurately having our pudding over-egged for us and not always with our consent; that we have far too many potential and actual partners all wanting to protect the patient, oversee the processes, give their opinion on what might be best in any particular situation and frankly, elbow their way in to what is at the end of the day our territory, our world and our professional responsibility. In following this line of thought I have inevitably to return in part to a theme of an editorial or so ago, that our patients come to us and continue to come to us because of trust and because we are professionals. I think it is getting to the time when we need to start reminding more people of this - more partners in fact.

To a greater or lesser extent we cannot always choose our partners, some are statutorily imposed, others arrive through the democratic process and yet more through administrative imperative. Yet we do still have some jurisdiction and some small but significant room to manoeuvre as individuals and collectively through the BDA and other channels of smaller representation. It may well be that we need to exercise these options and choices more carefully in the future and pay greater attention to the forces that are shaping our professional lives. Indeed, if we accept that such decisions are not just available if we can be bothered to make them but to actively seize them, then the likelihood of greater satisfaction and better patient care will follow the stronger.

Examples of this can be found with the various agencies described above. Proactively lobbying an MP or Minister, taking positive steps to influence a local councillor; forming influential alliances with primary care organisations, or perhaps with general medical practitioners if the future of health budgets goes that way, as it is predicted that it might. In the wider dental team of the future we will need to engage with these partners in ways that have not perhaps seemed possible or even necessary in the past. Similarly, we should not shy away from parting, hopefully amicably but possibly not, from people, agencies and partners who are not adding to the greater good, who are hamstringing our worlds with unproven and unnecessary burdens and who seek to interfere in ways that as trusted professionals we deem to be undermining and not underpinning our primary role in building better patient care. While we need to widen our team we also need to simultaneously focus on the narrower but essential path of what is best practice. That is our remit and our responsibility for which many should wish to partner us.

DOI: $10.1038 /$ sj.bdj.2010.888 